\title{
Multiple Comorbid Conditions among Middle-Aged and Elderly Hemophilia Patients: Prevalence Estimates and Implications for Future Care
}

\author{
Aroub A. Khleif, ${ }^{1}$ Nidra Rodriguez, ${ }^{1}$ Deborah Brown, ${ }^{1}$ and Miguel A. Escobar ${ }^{1,2}$ \\ ${ }^{1}$ Department of Pediatrics and Gulf States Hemophilia \& Thrombophilia Center, The University of Texas Health Science Center \\ at Houston, Houston, TX 77030, USA \\ ${ }^{2}$ Department of Internal Medicine and Gulf States Hemophilia \& Thrombophilia Center, The University of Texas Health Science Center \\ at Houston, Houston, TX 77030, USA \\ Correspondence should be addressed to Miguel A. Escobar, miguel.escobar@uth.tmc.edu \\ Received 21 March 2011; Revised 27 May 2011; Accepted 7 July 2011 \\ Academic Editor: Arshad Jahangir
}

Copyright ( 2011 Aroub A. Khleif et al. This is an open access article distributed under the Creative Commons Attribution License, which permits unrestricted use, distribution, and reproduction in any medium, provided the original work is properly cited.

\begin{abstract}
Introduction. Advances in hemophilia care and treatment have led to increases in the life expectancy among hemophiliacs. As a result, persons with hemophilia are reaching an older age and experiencing various age-related health conditions never seen before in this population. Aim. To determine the prevalence of comorbidities among middle-aged and elderly hemophilia A and hemophilia B patients. Methods. Retrospective chart review among all hemophilia patients, who attended the Gulf States Hemophilia and Thrombophilia Center. Results. All patients had at least one comorbid condition other than hemophilia, and the majority had between 3 and 6 comorbidities. The most common conditions identified were chronic hepatitis C, hypertension, HIV, chronic arthropathy, and overweight/obesity. Conclusions. Since persons with comorbidities are more likely to have poorer health outcomes and require greater care in managing their health needs, caring for aging hemophiliacs is likely to pose various social and economic challenges for both patients and providers.
\end{abstract}

\section{Introduction}

During the past three decades, the life expectancy for individuals with hemophilia A (a hereditary deficiency of coagulation factor VIII) and hemophilia B (a hereditary deficiency of coagulation factor IX) has markedly increased, primarily due to advances in medical care, as well as the introduction and availability of clotting factor replacement products and effective treatments for infectious diseases [1-10]. However, with this increased longevity and improved quality of life, comes a generation of middle-aged and elderly hemophiliacs that are experiencing age-related health conditions that have subsequently not been seen in this population $[1,6,10]$.

Prior to the availability of factor replacement therapy, the majority of patients with hemophilia died at an early age from bleeding problems $[2,4,11]$. Throughout the 1980s and 1990s, high death rates were observed, due to bloodborne viral infections, specifically human immunodeficiency virus (HIV) and the hepatitis $\mathrm{C}$ virus (HCV), and replaced bleeding complications as the primary cause of death among hemophiliacs [5, 12]. Nevertheless, barring the increased mortality rates discerned during this period, the life expectancy for patients with hemophilia, particularly those with mild or moderate hemophilia, in high and middle income nations, is currently drawing near to that of the general male population $[13,14]$.

While a variety of age-related co-morbidities have been reported among males in the general population, only a modest amount of information exists regarding these new causes of age-related morbidity and mortality and more specifically how to deal with these conditions among individuals with hemophilia $[1,5,6,11]$. The primary focus of this study was to identify and estimate the prevalence of co-morbid conditions that were associated with middle-aged and elderly hemophilia patients attending at Texas treatment 
center and evaluate the implications these conditions may have on future care among individuals in this population.

\section{Materials and Methods}

We conducted a retrospective study among adult patients, 40 years of age or greater, who had a clinical diagnosis of hemophilia A or hemophilia B, and attended the Gulf States Hemophilia and Thrombophilia Center (GSHTC) at least once between January 2007 and August 2010. The GSHTC is the largest treatment center in the southwest and one of the largest in the country.

Data were obtained from the patient's medical charts using a standardized data abstraction form, and information regarding the patient's demographic characteristics, as well as clinical and co-morbid conditions, was examined. Laboratory findings, in conjunction with physician notes as well as medication and problem lists from the patient's medical charts, were used to determine whether or not they had a specific comorbidity. Furthermore, the diagnostic criteria used to define individual co-morbid conditions are described in Table 1. Patients who met the inclusion criteria but died during the specified observation range were also included in the study. In addition, we defined comorbidity as the presence of one or more diseases/conditions, other than the patient's hemophilia disease.

Frequency distributions of demographic and treatmentrelated characteristics by hemophilia disease were examined. Differences between patients with hemophilia A and hemophilia B were assessed using Fischer's exact test. In addition, the prevalence of co-morbid conditions was examined among this patient cohort and compared to that of general US male population when data were available. All analyses were conducted using STATA statistical analysis software, version 11.0 [15].

\section{Results}

Characteristics of the study sample according to their disease status are summarized in Table 2. Between January 2007 and August 2010, the GSHTC saw a total of 404 hemophilia patients, roughly $16 \%$ were 40 years of age or greater. Of the 63 patients who met the inclusion criteria, the majority had hemophilia A, 71\%, respectively. The mean age of the cohort was approximately 53 years for patients with hemophilia A and 54 years among patients with hemophilia B. In addition, the majority of the sample visited the treatment center within one year of the observation period was treated on demand and had mild hemophilia. Patients with hemophilia A and hemophilia B did not differ significantly on any of the variables examined with the exception of race/ethnicity and employment status.

Table 3 presents the prevalence of specific co-morbidities among the study sample, including comparisons to the agematched, general US male population when data were available. Confidence limits were also estimated in order to draw comparisons to that of the general US population. However, due to the small sample size of the study cohort, it is difficult to draw significant comparisons of the representativeness of the prevalence estimates reported between our patient population and that of the general US male population. All patients in the study had at least one co-morbid condition other than their hemophilia disease, with the majority having between 3 and 6 conditions (mean number of conditions in the sample was 4). As expected, more than half of the sample suffered from hemophilic arthropathy, 55\% of which had severe hemophilia. Only $21 \%$ of the cohort (13 patients) did not have any blood-borne viral infections: $6 \%$ had hepatitis $\mathrm{B}$ virus (HBV) infection, 25\% had HIV, 78\% had HCV, $25 \%$ were coinfected with HIV and HCV, and 5\% had both $\mathrm{HBV}$ and HCV. Additionally, differences in co-morbidities between hemophilia A and hemophilia B patients were also examined. While the results did show differences between the groups with respect to their HIV, HCV, cardiovascular disease, renal disease, and arthropathy status, it is difficult to provide any meaningful statistically significant comparisons due to the small sample size of the study cohort.

A total of 5 patients (8\%) died during the study period. Causes of death included hepatocellular carcinoma (HCC), acute myeloid leukemia, and lung cancer, and 2 patients died from accidental, nonmedical factors. Additionally, 5 patients in the sample, all of whom had hemophilia A (1 patient had mild hemophilia A, and 4 patients had severe hemophilia A), received a liver transplant during the observation period. Among patients receiving a liver transplant, $80 \%$ were diagnosed with end-stage liver disease due to HCV.

Over three-fourths (78\%) of the study population had at least one cardiovascular risk factor including hypertension (46\%), a body mass index (BMI) of 25.0 or higher ( $65 \%$ of the sample was overweight or obese), high cholesterol (16\%), and diabetes mellitus (14\%). In addition, the prevalence of other co-morbidities that were examined among patients in this population are reported in Table 2 and include renal disease (8\%), thyroid disease (6\%), depression (8\%), neurological disease (5\%) including Parkinson's disease, epilepsy, and dementia, respiratory disease (11\%) including asthma, sleep apnea, sarcoidosis, and chronic obstructive pulmonary disease, and gastrointestinal disease (5\%) including peptic ulcer disease and acid reflux disease.

\section{Discussion}

This study revealed a variety of notable differences with regard to comparing the prevalence of multiple co-morbid conditions among middle-aged and elderly hemophilia $\mathrm{A}$ and hemophilia B patients to that of the general US male population. Previous research has suggested that as much as $62 \%$ of the US population over the age of 65 have more than one co-morbid condition [21]. Results from this study indicated that all of the patients in this sample had more than one co-morbid condition other than their underlying hemophilia disease, and roughly $19 \%$ of the cohort over the age of 65 had at minimum 3 or more co-morbid conditions.

As noted in previous studies, the prevalence of HIV and $\mathrm{HCV}$ infections are considerably higher among hemophiliacs than in the general male population $[4,5]$ and are a leading cause of morbidity and mortality in this population $[2,22$, 23]. It is estimated that greater than $90 \%$ of hemophiliacs 
TABle 1: Diagnostic criteria for defining co-morbid conditions.

\begin{tabular}{|c|c|}
\hline Condition & Criteria $^{\ddagger}$ \\
\hline \multirow{2}{*}{ Human immunodeficiency virus } & HIV-1 PCR quantification \\
\hline & On drug therapy (HAART) \\
\hline \multirow{2}{*}{ Hepatitis C virus } & HCV RNA \\
\hline & On or received drug therapy \\
\hline \multirow{3}{*}{ Overweight/obesity } & $\begin{array}{l}\text { Based on their } \mathrm{BMI}^{\dagger} \text { score, patients were categorized as overweight or } \\
\text { obese based on the following: }\end{array}$ \\
\hline & Overweight: $25.0-29.9$ \\
\hline & Obesity: 30.0 and above \\
\hline \multirow{4}{*}{ Cardiovascular disease } & Echocardiogram findings \\
\hline & Electrocardiogram findings \\
\hline & On drug therapy \\
\hline & Cardiologist notes \\
\hline \multirow{4}{*}{ Hypertension } & $\geq 130 \mathrm{mmHg}$ systolic blood pressure \\
\hline & $\geq 85 \mathrm{mmHg}$ diastolic blood pressure \\
\hline & Primary care physician notes \\
\hline & On drug therapy for elevated blood pressure \\
\hline \multirow{3}{*}{ Hypercholesterolemia } & Lipid profile \\
\hline & On drug therapy for high lipids \\
\hline & Primary care physician notes \\
\hline \multirow{2}{*}{ Chronic arthropathy } & Physical findings \\
\hline & Radiographic findings \\
\hline Hepatitis B virus & Hepatitis B surface antigen detected for more than 6 months \\
\hline \multirow{2}{*}{ Diabetes } & Primary care physician notes \\
\hline & On drug therapy \\
\hline \multirow{4}{*}{ Renal disease } & Patient is on dialysis \\
\hline & Pathology results from biopsy \\
\hline & Estimation of glomerular filtration rate (GFR) \\
\hline & Nephrologist notes \\
\hline \multirow{2}{*}{ Depression } & On drug therapy \\
\hline & Psychiatry notes \\
\hline \multirow{3}{*}{ Respiratory diseases } & Positive radiographic findings \\
\hline & Primary care physician notes \\
\hline & On drug therapy or continuous positive airway pressure (CPAP) therapy \\
\hline \multirow{3}{*}{ Gastrointestinal diseases } & Gastroenterologist notes \\
\hline & Endoscopy findings \\
\hline & On drug therapy \\
\hline Thyroid disease & On drug therapy \\
\hline \multirow{2}{*}{ Neurological disease } & Neurologist or primary care physician notes \\
\hline & On drug therapy \\
\hline \multirow{3}{*}{ Cancer } & Oncologist notes \\
\hline & Pathology reports \\
\hline & Radiographic findings \\
\hline
\end{tabular}

${ }^{\ddagger}$ Patient was considered to have a specific comorbidity if any of the criteria for that condition was indicated in their chart.

${ }^{\dagger}$ National Center for Health Statistics. Health, United States, 2009, Hyattsville, MD, 2010.

who were treated with plasma-derived factor concentrates before 1985 became infected with $\mathrm{HCV}$, and greater than $55 \%$ of these patients were also coinfected with HIV [24]. Among patients in this cohort who were between 40 and 49 years of age $(N=29)$, the prevalence of HIV infection was approximately $38 \%$ compared to $0.74 \%$ among agematched males in the US. In addition, the prevalence of HCV infection in our patient sample was 12 to 90 times higher than in the age-matched male population ( $40-49$ years: $72 \%$ versus $6 \%$; $50-59$ years: $83 \%$ versus $1.6 \%$; $\geq 60$ years: $81 \%$ 
TABle 2: Selected characteristics of patients 40 years of age or greater, who visited the Gulf States Hemophilia \& Thrombophilia Center between January 1, 2007 and August 31, 2010, according to disease status.

\begin{tabular}{|c|c|c|c|c|c|c|c|}
\hline \multirow{2}{*}{ Characteristics } & \multicolumn{2}{|c|}{ Hemophilia A $(N=45)$} & \multicolumn{2}{|c|}{ Hemophilia B $(N=18)$} & \multicolumn{2}{|c|}{ Total $(N=63)$} & \multirow{2}{*}{$P$ value $^{\dagger}$} \\
\hline & $n$ & $\%$ & $n$ & $\%$ & $N$ & $\%$ & \\
\hline All patients & & 71.4 & & 28.6 & & & \\
\hline Age in years & & & & & & & 0.715 \\
\hline $40-49$ & 21 & 46.6 & 8 & 44.5 & 29 & 46.0 & \\
\hline $50-59$ & 14 & 31.1 & 4 & 22.2 & 18 & 28.6 & \\
\hline $60-69$ & 7 & 15.6 & 4 & 22.2 & 11 & 17.5 & \\
\hline$\geq 70$ & 3 & 6.7 & 2 & 11.1 & 5 & 7.9 & \\
\hline Race/ethnicity & & & & & & & 0.002 \\
\hline Caucasian (non-Hispanic) & 26 & 57.8 & 8 & 44.4 & 34 & 54.0 & \\
\hline Hispanic & 16 & 35.5 & 2 & 11.2 & 18 & 28.6 & \\
\hline African American & 3 & 6.7 & 8 & 44.4 & 11 & 17.4 & \\
\hline Employment status & & & & & & & 0.032 \\
\hline Employed full-time & 18 & 40.0 & 3 & 16.6 & 21 & 33.4 & \\
\hline Employed part-time & 5 & 11.1 & 0 & - & 5 & 7.9 & \\
\hline Unemployed & 22 & 48.9 & 14 & 77.8 & 36 & 57.1 & \\
\hline Unknown & 0 & - & 1 & 5.6 & 1 & 1.6 & \\
\hline Insurance status & & & & & & & 0.283 \\
\hline Commercial insurance & 18 & 40.0 & 8 & 44.4 & 26 & 41.3 & \\
\hline Medicare & 13 & 28.9 & 9 & 50.0 & 22 & 34.9 & \\
\hline Medicaid & 5 & 11.1 & 0 & - & 5 & 7.9 & \\
\hline State high risk & 1 & 2.2 & 0 & - & 1 & 1.6 & \\
\hline Uninsured & 8 & 17.8 & 1 & 5.6 & 9 & 14.3 & \\
\hline Disease severity & & & & & & & 0.694 \\
\hline Mild (6\%-50\%) & 23 & 51.1 & 9 & 50.0 & 32 & 50.8 & \\
\hline Moderate (1\%-5\%) & 6 & 13.3 & 4 & 22.2 & 10 & 15.9 & \\
\hline Severe $(<1 \%)$ & 16 & 35.6 & 5 & 27.8 & 21 & 33.3 & \\
\hline Treatment type & & & & & & & 0.248 \\
\hline On demand & 35 & 77.8 & 15 & 83.3 & 50 & 79.4 & \\
\hline Intermittent prophylaxis & 0 & - & 1 & 5.6 & 1 & 1.6 & \\
\hline Continuous prophylaxis & 10 & 22.2 & 2 & 11.1 & 12 & 19.0 & \\
\hline Last visit to treatment center & & & & & & & 0.201 \\
\hline$<1$ year ago & 30 & 66.7 & 13 & 72.2 & 43 & 68.3 & \\
\hline $1-2$ years ago & 5 & 11.1 & 4 & 22.2 & 9 & 14.3 & \\
\hline$>2$ years ago & 10 & 22.2 & 1 & 5.6 & 11 & 17.4 & \\
\hline
\end{tabular}

${ }^{\dagger}$ Due to small sample sizes, $P$ value for Fischer's Exact Test is reported.

versus $0.9 \%$ ). Furthermore, chronic HCV infection is a major risk factor in the development of liver cirrhosis and HCC $[11,25]$, and, subsequently, HCC has emerged as a significant cause of mortality among HCV-infected hemophiliacs [11]. Roughly $11 \%$ of patients in this sample who were diagnosed with HCV progressed to HCC; one patient died, and more than half $(57 \%)$ received a liver transplant. Since the risk of HCC among HCV-infected hemophilia patients increases with older age and the presence of HIV infection $[11,22,23]$, it is expected that many of the HCV-infected patients in this sample will progress to end-stage liver disease or HCC.

While cardiovascular disease (CVD) has been the primary cause of death among individuals in the US for the past eight decades [26], several studies have reported that mortality from cardiac events among individuals with hemophilia is lower than in the general population $[7,8$,
$13,27,28]$ and hemophilia may actually have a protective effect against CVD $[4,11,28]$. The prevalence of CVD among patients between 40 and 59 years of age in this study was similar compared to the age-matched US male population ( $40 \%$ versus $39 \%$ ), but slightly lower among those patients of 60 years of age or greater (69\% versus $71 \%)$. However, it should be noted that in order to provide comparisons between this cohort to that of age-matched males in the US, patients with CVD were defined as having any of the following conditions (based on the National Center for Health Statistics definition): congestive heart disease, heart failure, stroke, and hypertension. If we excluded hypertension from the analysis and defined CVD as having only one of the following conditions: congestive heart disease, heart failure and/or stroke, the prevalence of CVD among all patients in the study was approximately $11 \%$. 
TABle 3: Prevalence estimates and 95\% confidence intervals of co-morbid conditions among hemophilia patients compared to the general US male population, by selected characteristics.

\begin{tabular}{|c|c|c|c|c|}
\hline \multirow{2}{*}{ Condition } & \multicolumn{3}{|c|}{ Hemophilia A and B patients $(N=63)$} & \multirow{2}{*}{$\begin{array}{c}\text { Prevalence in general US male population } \\
\%\end{array}$} \\
\hline & $n$ & $\%$ & $95 \% \mathrm{CI}^{\ddagger}$ & \\
\hline \multicolumn{5}{|l|}{$\begin{array}{l}\text { Total number of co-morbid } \\
\text { conditions }{ }^{\dagger \dagger}\end{array}$} \\
\hline $1-2$ & 16 & 25.4 & $14.35,36.45$ & \\
\hline $3-4$ & 22 & 34.9 & $22.82,47.02$ & \\
\hline $5-6$ & 17 & 27.0 & $15.72,38.25$ & \\
\hline$\geq 7$ & 8 & 12.7 & $4.24,21.15$ & \\
\hline HIV positive & 16 & 25.4 & $14.35,36.45$ & \multirow{2}{*}{ a $40-49$ years: 0.74} \\
\hline $40-49$ years & 11 & 37.9 & $19.15,56.71$ & \\
\hline HCV positive & 49 & 77.8 & $67.22,88.33$ & \multirow{4}{*}{$\begin{array}{l}\text { b } 40-49 \text { years: } \sim 6 \\
50-59: 1.6 \\
\geq 60 \text { years: } 0.9\end{array}$} \\
\hline $40-49$ years & 21 & 72.4 & $55.11,89.72$ & \\
\hline $50-59$ years & 15 & 83.3 & $64.26,99.02$ & \\
\hline$\geq 60$ years & 13 & 81.3 & $59.77,99.03$ & \\
\hline \multicolumn{5}{|l|}{ BMI } \\
\hline Normal (18.5-24.9) & 22 & 34.9 & $22.82,47.02$ & \\
\hline Overweight (25.0-29.9) & 25 & 39.7 & $27.26,52.10$ & \\
\hline Obese $(\geq 30)$ & 16 & 25.4 & $14.34,36.45$ & \\
\hline $\mathrm{BMI} \geq 25.0$ & & & & \multirow{3}{*}{$\begin{array}{l}{ }^{\mathrm{c}} \mathrm{BMI} \geq 25.0 \\
40-59 \text { years: } 77.8 \\
\geq 60 \text { years: } 78.4\end{array}$} \\
\hline $40-59$ years & 33 & 70.2 & $56.64,83.79$ & \\
\hline$\geq 60$ years & 8 & 50.0 & $22.48,77.52$ & \\
\hline $\mathrm{BMI} \geq 30.0$ & & & & \multirow{3}{*}{$\begin{array}{l}{ }^{\mathrm{c}} \mathrm{BMI} \geq 30.0 \\
40-59 \text { years: } 34.3 \\
\geq 60 \text { years: } 37.1\end{array}$} \\
\hline $40-59$ years & 13 & 27.7 & $14.38,40.93$ & \\
\hline$\geq 60$ years & 3 & 18.8 & - & \\
\hline $\mathrm{BMI} \geq 35.0$ & & & & \multirow{3}{*}{$\begin{array}{l}{ }^{\mathrm{c}} \mathrm{BMI} \geq 35.0 \\
40-59 \text { years: } 11.6 \\
\geq 60 \text { years: } 11.6\end{array}$} \\
\hline $40-59$ years & 6 & 12.8 & $2.8,22.67$ & \\
\hline$\geq 60$ years & 1 & 6.3 & - & \\
\hline $\mathrm{BMI} \geq 40.0$ & & & & \multirow{3}{*}{$\begin{array}{l}{ }^{\mathrm{c}} \mathrm{BMI} \geq 40.0 \\
40-59 \text { years: } 4.2 \\
\geq 60 \text { years: } 4.2\end{array}$} \\
\hline $40-59$ years & 2 & 4.3 & - & \\
\hline$\geq 60$ years & - & - & - & \\
\hline Cardiovascular disease $\mathrm{e}^{\dagger \dagger \dagger}$ & 30 & 47.6 & $34.94,60.30$ & \multirow{3}{*}{$\begin{array}{l}{ }^{\mathrm{d}} 40-59 \text { years: } 39.1 \\
\geq 60 \text { years: } 71.3\end{array}$} \\
\hline $40-59$ years & 19 & 40.4 & $25.86,54.99$ & \\
\hline$\geq 60$ years & 11 & 68.8 & $43.24,94.26$ & \\
\hline Hypertension & 29 & 46.0 & $33.38,58.69$ & \multirow{6}{*}{$\begin{array}{l}{ }^{\mathrm{e}} 45-54 \text { years: } 36.2 \\
55-64 \text { years: } 50.2 \\
65-74 \text { years: } 64.1 \\
\geq 75 \text { years: } 65.0\end{array}$} \\
\hline 40-44 years & 6 & 46.2 & $14.80,77.51$ & \\
\hline $45-54$ years & 7 & 30.4 & $10.09,50.78$ & \\
\hline $55-64$ years & 8 & 53.3 & $24.74,81.93$ & \\
\hline $65-74$ years & 6 & 60.0 & $23.06,96.94$ & \\
\hline$\geq 75$ years & 2 & 100 & - & \\
\hline Hypercholesterolemia & 10 & 15.9 & $6.60,25.15$ & \multirow{5}{*}{$\begin{array}{l}{ }^{\mathrm{e}} 45-54 \text { years: } 36.2 \\
55-64 \text { years: } 50.2 \\
65-74 \text { years: } 64.1 \\
\geq 75 \text { years: } 65.0\end{array}$} \\
\hline $45-54$ years & 4 & 17.4 & $0.63,34.15$ & \\
\hline 55-64 years & 2 & 13.3 & - & \\
\hline $65-74$ years & 2 & 20.0 & - & \\
\hline$\geq 75$ years & 1 & 50.0 & - & \\
\hline Chronic arthropathy & 33 & 52.4 & $39.70,65.06$ & \\
\hline 40-59 years & 22 & 46.8 & $32.00,61.62$ & \\
\hline$\geq 60$ years & 11 & 68.8 & $43.24,94.26$ & \\
\hline
\end{tabular}


Table 3: Continued.

\begin{tabular}{|c|c|c|c|c|}
\hline \multirow{2}{*}{ Condition } & \multicolumn{3}{|c|}{ Hemophilia A and B patients $(N=63)$} & \multirow{2}{*}{$\begin{array}{c}\text { Prevalence in general US male population }^{\dagger} \\
\% \\
\end{array}$} \\
\hline & $n$ & $\%$ & $95 \% \mathrm{CI}^{\ddagger}$ & \\
\hline HBV positive & 4 & 6.4 & $0.16,12.54$ & \\
\hline Diabetes & 9 & 14.3 & $5.40,23.17$ & \\
\hline Renal disease & 5 & 7.9 & $1.07,14.80$ & \\
\hline Depression & 5 & 7.9 & $1.07,14.80$ & \\
\hline Respiratory disease & 7 & 11.1 & $3.13,19.09$ & \\
\hline Gastrointestinal disease & 3 & 4.8 & - & \\
\hline Thyroid disease & 4 & 6.4 & $0.16,12.54$ & \\
\hline Neurological disease & 3 & 4.8 & - & \\
\hline Cancer & 10 & 15.9 & $6.60,25.15$ & \\
\hline Hepatocellular carcinoma & 7 & 70.0 & & \\
\hline Non-Hodgkin's lymphoma & 1 & 10.0 & & \\
\hline Lung cancer & 1 & 10.0 & & \\
\hline Leukemia & 1 & 10.0 & & \\
\hline
\end{tabular}

${ }^{\ddagger}$ CI: Confidence interval,

${ }^{\dagger}$ Prevalence estimates reported when data were available:

${ }^{\mathrm{a}}$ see [16].

$\mathrm{b}_{\text {see }[17] \text {. }}$.

${ }^{\mathrm{c}}$ see [18].

$\mathrm{d}_{\text {see }[19] .}$.

esee [20].

${ }^{\dagger \dagger}$ Number of conditions excluding hemophilia disease.

${ }^{\dagger \dagger \dagger}$ Includes patients with cardiovascular disease, hypertension, and stroke.

Despite conflicting reports regarding a possible protective effect against CVD among individuals with hemophilia $[4,11,28]$, common risk factors for CVD including hypertension, high cholesterol, diabetes mellitus (DM), and overweight/obesity were observed among patients in this study. The prevalence of hypertension was lower compared to the US population among all age groups except among patients between 55 and 64 years of age. No differences were observed between our patient population and the agematched general population with respect to high cholesterol. While over $65 \%$ of this cohort was overweight or obese, these rates were lower compared to the age-matched population. In addition, overweight and obesity were more prevalent among patients with mild hemophilia (72\%), which is similar to a finding reported in a previous study [29].

An increased bodyweight is an important risk factor associated not only with CVD, but also in the development of DM and chronic arthropathy. Only a limited amount of information exists regarding the prevalence of DM among hemophiliacs. The study conducted by Walsh et al. [30] estimated that the prevalence of DM among mild hemophiliacs was $24 \%$ compared to $6 \%$ in control males (mean age of subjects in both groups was 46 years of age) [30]. The prevalence of DM among all patients in this sample was $14 \%$, and roughly $89 \%$ of those patients who had DM also had a BMI greater than 25 .

The majority of hemophiliacs born prior to the availability of prophylactic therapy suffer from hemophilic arthropathy [4], which continues to be the primary cause of morbidity among individuals in this population [2]. As expected, half of the patients in this cohort suffer from chronic arthropathy, of which $56 \%$ had severe hemophilia and $53 \%$ had a BMI of 25 or higher. In addition, overweight and obesity may have greater implications on persons with hemophilia due to the fact that an increased bodyweight may cause additional damage to already deteriorated joints [29]. Furthermore, since the dosage of factor replacement treatment is based on bodyweight, the costs of care are much higher among overweight and obese patients compared with patients with a normal bodyweight.

Renal disease is another age-related medical condition that affects hemophiliacs, who are reported to have up to a 50-fold increase in mortality due to renal failure compared to the general population [31]. Previous research has indicated that risk factors for renal failure among individuals with hemophilia include increased age, hypertension, and HIV co-infection [1,32]. Approximately $8 \%$ of patients in this sample had chronic renal disease, $20 \%$ of which also had HIV, and $40 \%$ of which had hypertension. With the mean age of all patients in this cohort being 53 years of age, it is likely that more cases of renal disease will be observed as the population continues to age.

While hemophilia care has undergone substantial advancements during the past three decades, a variety of healthcare needs arising from many of the age-related co-morbidities mentioned in this paper pose significant challenges for the treatment and management of these conditions among aging hemophiliacs. Currently, there are few evidence-based guidelines that direct medical professionals on how to most effectively manage the comprehensive care 
needs of hemophilia patients with these age-related comorbidities [1, 11]. As a result, optimal treatment and care for hemophiliacs with multiple co-morbid conditions has been challenging for both healthcare providers and the patient.

Further studies are needed to document the safety and efficacy of certain drug therapies, procedures, and lifestyle changes among aging hemophiliacs with multiple co-morbid conditions. For example, no explicit guidelines are available for addressing CVD risk in persons with hemophilia. While there are modifiable lifestyle factors that can be addressed including diet, exercise, and smoking cessation programs [11], safety of frequent aspirin use needs to be evaluated as this could cause an increase in the bleeding frequency among hemophiliacs. In addition, with regard to lifestyle factors such as exercise and activity programs to help reduce the risk of CVD as well as other conditions such as overweight/obesity and diabetes, these may not be practical and/or may be difficult particularly for patients with chronic arthropathy. Support from physical therapists at treatment centers may play a critical role in promoting an active lifestyle within the boundaries of a patient's abilities.

Given the complexities associated with how to best care for and treat hemophiliacs with multiple co-morbid conditions, successful management must entail a multifaceted approach, which encompasses drawing from expertise not only from hematology, but that of cardiology, oncology, urology, infectious disease, orthopedics, hepatology, nephrology, and internal medicine. A lack of coordination between these various departments may affect the delivery of appropriate and timely healthcare services. Hemophilia treatment centers should play an essential role in coordinating the care for these patients to ensure they are knowledgeable of the services they need as well as understand the implications associated with seeking timely care from these services. However, management and treatment requirements for specific comorbidities need to be an interdisciplinary effort, and hemophilia treatment centers cannot be the sole caregivers for hemophiliacs with multiple co-morbidities. As such, lifestyle issues as well as general screening programs should be incorporated in the management and treatment plans, including assistance with timely referrals and followup with appropriate specialty services for aging hemophilia patients attending treatment centers.

\section{Conclusions}

Individuals with multiple co-morbid conditions tend to receive suboptimal care, which can lead to poorer health outcomes and increased treatment costs. In addition, the challenge of providing adequate care increases in complexity as the number of chronic conditions increases [21, 33], resulting in disproportionately high health care costs. It is estimated that over $75 \%$ of health care expenditures in the US are spent on care for persons with multiple co-morbidities [21] and the average spending per person with co-morbidities is roughly five times greater compared with individuals with no chronic conditions [33]. As the world population of persons with hemophilia ages, an increase in age-related health conditions not previously seen in this population are likely to become more prevalent. Hemophilia is an already costly disease, and understanding both treatment care needs and its related costs among aging hemophiliacs with multiple co-morbidities is critical in order to provide optimal care and manage their comprehensive health needs effectively. While this study identified a variety of co-morbidities associated with middle-aged and elderly hemophiliacs, only 63 patients were included in the cohort, thus making it difficult to provide any statistically significant comparisons. Moreover, due to the small sample size of the cohort, our estimates of co-morbidities make it difficult to draw significant comparisons between our hemophilia patient population and the general US male population. In addition, since patients were classified as having a specific condition based on information available in their medical charts, the possibility of underestimating certain comorbidities may be of concern. Further research, particularly larger, multicenter, prospective studies are needed to identify how to best care for and treat aging hemophilia patients with multiple co-morbidities.

\section{References}

[1] G. Dolan, "The challenge of an ageing haemophilic population," Haemophilia, vol. 16, no. 5, pp. 11-16, 2010.

[2] M. Franchini and P. M. Mannucci, "Co-morbidities and quality of life in elderly persons with haemophilia," British Journal of Haematology, vol. 148, no. 4, pp. 522-533, 2010.

[3] E. Ikkala, T. Hilske, and G. Myllyla, "Changes in the life expectancy of patients with severe haemophilia A in Finland in 1930-1979," British Journal of Haematology, vol. 52, no. 1, pp. 7-12, 1982.

[4] E. P. Mauser-Bunschoten, D. E. Fransen Van De Putte, and R. E. G. Schutgens, "Co-morbidity in the ageing haemophilia patient: the down side of increased life expectancy," Haemophilia, vol. 15, no. 4, pp. 853-863, 2009.

[5] W. Miesbach, S. Alesci, S. Krekeler, and E. Seifried, "Comorbidities and bleeding pattern in elderly haemophilia A patients," Haemophilia, vol. 15, no. 4, pp. 894-899, 2009.

[6] J. Oldenburg, G. Dolan, and G. Lemm, "Haemophilia care then, now and in the future," Haemophilia, vol. 15, no. 1, pp. $2-7,2009$.

[7] I. Plug, J. G. Van Der Bom, M. Peters et al., "Mortality and causes of death in patients with hemophilia, 19922001: a prospective cohort study," Journal of Thrombosis and Haemostasis, vol. 4, no. 3, pp. 510-516, 2006.

[8] F. R. Rosendaal, I. Varekamp, C. Smit et al., "Mortality and causes of death in Dutch haemophiliacs, 1973-1986," British Journal of Haematology, vol. 71, no. 1, pp. 71-76, 1989.

[9] S. M. Siboni, P. M. Mannucci, A. Gringeri et al., "Health status and quality of life of elderly persons with severe hemophilia born before the advent of modern replacement therapy," Journal of Thrombosis and Haemostasis, vol. 7, no. 5, pp. 780786, 2009.

[10] A. M. Street, K. Hill, B. Sussex, M. Warner, and M. F. Scully, "Haemophilia and ageing," Haemophilia, vol. 12, no. 3, pp. 812, 2006.

[11] B. A. Konkle, C. Kessler, L. Aledort et al., "Emerging clinical concerns in the ageing haemophilia patient," Haemophilia, vol. 15, no. 6, pp. 1197-1209, 2009. 
[12] D. M. Arnold, J. A. Julian, and I. R. Walker, "Mortality rates and causes of death among all HIV-positive individuals with hemophilia in Canada over 21 years of follow-up," Blood, vol. 108, no. 2, pp. 460-464, 2006.

[13] S. C. Darby, W. K. Sau, R. J. Spooner et al., "Mortality rates, life expectancy, and causes of death in people with hemophilia A or B in the United Kingdom who were not infected with HIV," Blood, vol. 110, no. 3, pp. 815-825, 2007.

[14] P. M. Mannucci, R. E. G. Schutgens, E. Santagostino, and E. P. Mauser-Bunschoten, "How I treat age-related morbidities in elderly persons with hemophilia," Blood, vol. 114, no. 26, pp. 5256-5263, 2009.

[15] StataCorp, Stata Statistical Software, Release 11.0, Stata Corporation, College Station, Tex, USA.

[16] G. M. McQuillan, D. Kruszon-Moran, B. J. Kottiri et al., "Prevalence of HIV in the US household population: the national health and nutrition examination surveys, 1988 to 2002," Journal of Acquired Immune Deficiency Syndromes, vol. 41, no. 5, pp. 651-656, 2006.

[17] G. L. Armstrong, A. Wasley, E. P. Simard, G. M. McQuillan, W. L. Kuhnert, and M. J. Alter, "The prevalence of hepatitis C virus infection in the United States, 1999 through 2002," Annals of Internal Medicine, vol. 144, no. 10, pp. 705-714, 2006.

[18] K. M. Flegal, M. D. Carroll, C. L. Ogden, and L. R. Curtin, "Prevalence and trends in obesity among US adults, 19992008," Journal of the American Medical Association, vol. 303, no. 3, pp. 235-241, 2010.

[19] W. Rosamond, K. Flegal, K. Furie et al., "Heart disease and stroke statistics-2008 update: a report from the American heart association statistics committee and stroke statistics subcommittee," Circulation, vol. 117, no. 4, pp. e25-e146, 2008.

[20] National Center for Health Statistics, "Health, United States, 2009," Tech. Rep., National Center for Health Statistics, Hyattsville, Md, USA, 2010.

[21] C. Vogeli, A. E. Shields, T. A. Lee et al., "Multiple chronic conditions: prevalence, health consequences, and implications for quality, care management, and costs," Journal of General Internal Medicine, vol. 22, no. 3, pp. 391-395, 2007.

[22] G. Dolan, C. Hermans, R. Klamroth, R. Madhok, R. E. G. Schutgens, and U. Spencer, "Challenges and controversies in haemophilia care in adulthood," Haemophilia, vol. 15, no. 1, pp. 20-27, 2009.

[23] M. G. Rumi, F. De Filippi, E. Santagostino, and M. Colombo, "Hepatitis C in haemophilia: lights and shadows," Haemophilia, Supplement, vol. 10, no. 4, pp. 211-215, 2004.

[24] B. Kupfer, T. Ruf, B. Matz et al., "Comparison of GB virus C, $\mathrm{HIV}$, and HCV infection markers in hemophiliacs exposed to non-inactivated or inactivated factor concentrates," Journal of Clinical Virology, vol. 34, no. 1, pp. 42-47, 2005.

[25] S. F. Altekruse, K. A. McGlynn, and M. E. Reichman, "Hepatocellular carcinoma incidence, mortality, and survival trends in the United States from 1975 to 2005," Journal of Clinical Oncology, vol. 27, no. 9, pp. 1485-1491, 2009.

[26] J. R. Neyer, K. J. Greenlund, C. H. Denny, N. L. Keenan, D. R. Labarthe, and J. B. Croft, "Prevalence of heart disease-United States, 2005," Morbidity and Mortality Weekly Report, vol. 56, no. 6, pp. 113-118, 2007.

[27] R. Kulkarni, J. M. Soucie, B. L. Evatt et al., "Prevalence and risk factors for heart disease among males with hemophilia," American Journal of Hematology, vol. 79, no. 1, pp. 36-42, 2005.
[28] A. Tuinenburg, E. P. Mauser-Bunschoten, M. C. Verhaar, D. H. Biesma, and R. E.G. Schutgens, "Cardiovascular disease in patients with hemophilia," Journal of Thrombosis and Haemostasis, vol. 7, no. 2, pp. 247-254, 2009.

[29] F. G. Hofstede, K. Fijnvandraat, I. Plug, P. W. Kamphuisen, F. R. Rosendaal, and M. Peters, "Obesity: a new disaster for haemophilic patients? A nationwide survey," Haemophilia, vol. 14, no. 5, pp. 1035-1038, 2008.

[30] M. Walsh, D. Macgregor, S. Stuckless, B. Barrett, M. Kawaja, and M. F. Scully, "Health-related quality of life in a cohort of adult patients with mild hemophilia A," Journal of Thrombosis and Haemostasis, vol. 6, no. 5, pp. 755-761, 2008.

[31] J. M. Soucie, R. Nuss, B. Evatt et al., "Mortality among males with hemophilia: relations with source of medical care," Blood, vol. 96, no. 2, pp. 437-442, 2000.

[32] A. Lambing, P. Kuriakose, J. Lanzon, and E. Kachalsky, "Dialysis in the haemophilia patient: a practical approach to care," Haemophilia, vol. 15, no. 1, pp. 33-42, 2009.

[33] J. M. Valderas, B. Starfield, B. Sibbald, C. Salisbury, and M. Roland, "Defining comorbidity: implications for understanding health and health services," Annals of Family Medicine, vol. 7, no. 4, pp. 357-363, 2009. 


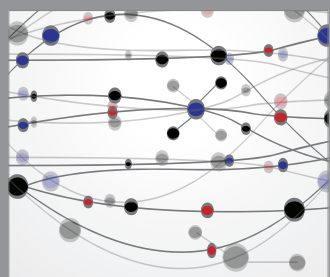

The Scientific World Journal
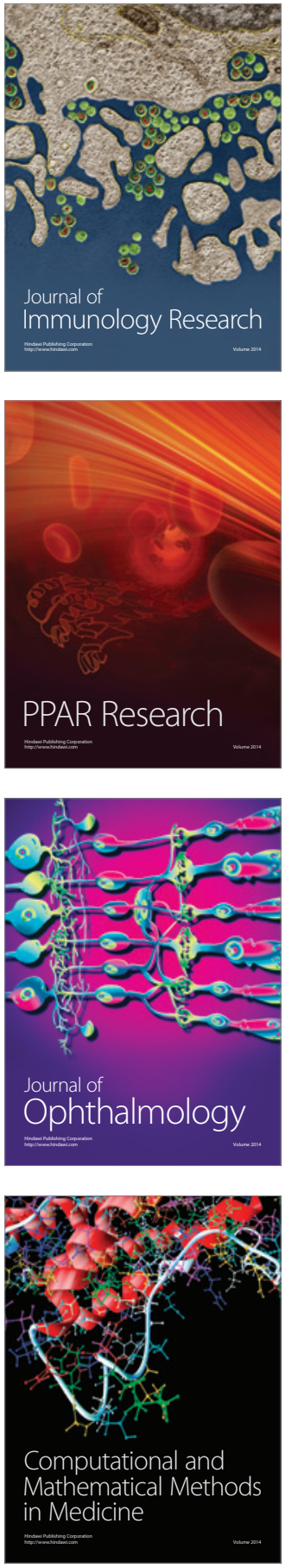

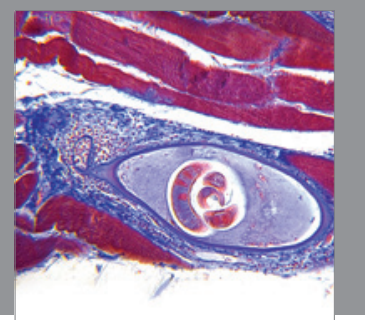

Gastroenterology

Research and Practice
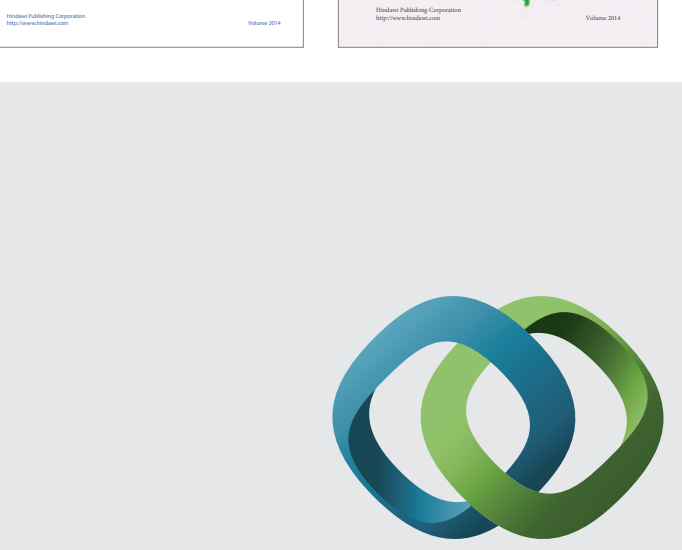

\section{Hindawi}

Submit your manuscripts at

http://www.hindawi.com
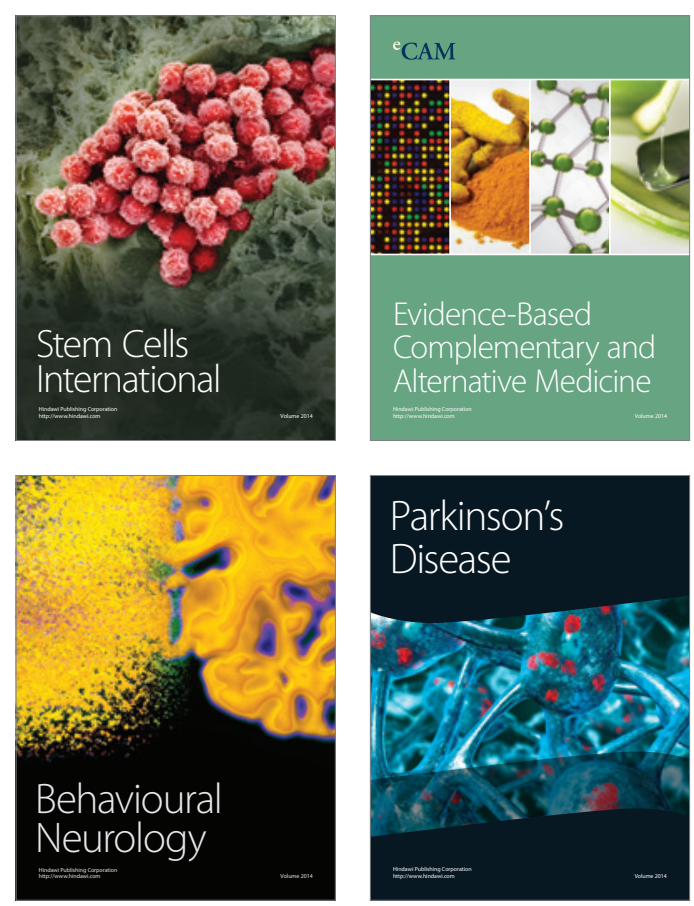

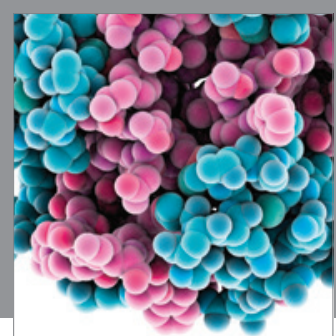

Journal of
Diabetes Research

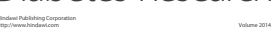

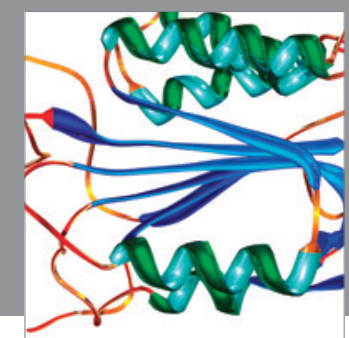

Disease Markers
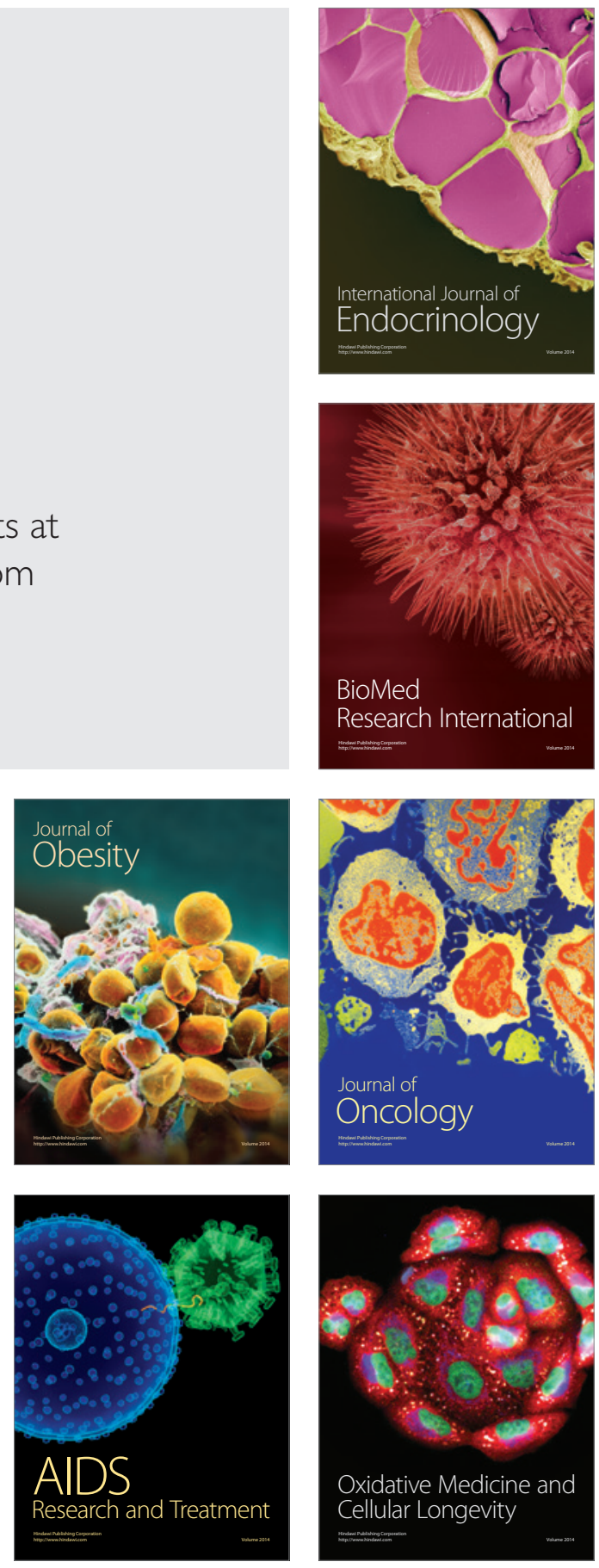